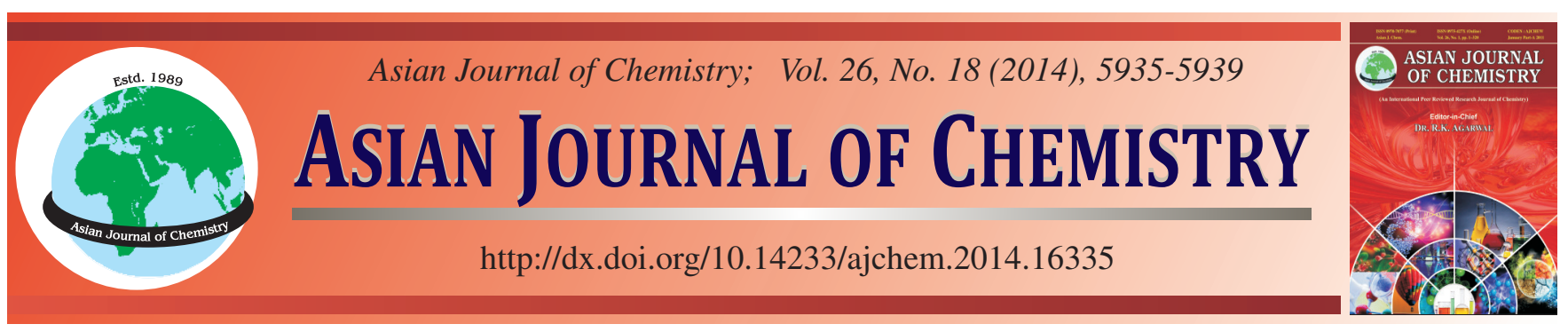

\title{
Stability of Endohedral Hydrogen Doped Boron Nitride Nanocages: A Density Functional Theory Study
}

\author{
S. SAYHAN and A. KINAL ${ }^{*}$
}

Department of Chemistry, Science Faculty, Ege University, 35100 Bornova, Izmir, Turkey

*Corresponding author: Fax: +90 232 3888264; Tel: +90 232 3112395; E-mail: armagan.kinal@ege.edu.tr

\begin{abstract}
In this study, the stabilization energies of the $\mathrm{nH}_{2} @ \mathrm{~B}_{\mathrm{m}} \mathrm{N}_{\mathrm{m}}$ complexes $(\mathrm{m}=12,24,36,48,60)$ have been determined by exploiting several density functional theory methods, namely B3LYP, PBE1PBE and $\omega$ B97X-D. Among these density functional theory methods, $\omega$ B97X-D is found to be the most appropriate for the systems involving $\mathrm{H}_{2}$ doping in boron nitride nanocages. It predicted that the smallest nanocage, $\mathrm{B}_{12} \mathrm{~N}_{12}$, has no stable complex and the $\mathrm{H}_{2} @ \mathrm{~B}_{24} \mathrm{~N}_{24}, 2 \mathrm{H}_{2} @ \mathrm{~B}_{36} \mathrm{~N}_{36}, 4 \mathrm{H}_{2} @ \mathrm{~B}_{48} \mathrm{~N}_{48}$ and $7 \mathrm{H}_{2} @ \mathrm{~B}_{60} \mathrm{~N}_{60}$ complexes are the most stable hydrogenboron nitride complexes. Accordingly, it is found that the number of hydrogen molecules doped inside the most stable complex of each nanocage quadratically depends on nanocage size. This indicates that as the size of nanocage, as well as, the size of the endohedral cavity increases more stable $\mathrm{nH}_{2} @ \mathrm{~B}_{\mathrm{m}} \mathrm{N}_{\mathrm{m}}$ complexes are formed.
\end{abstract}

Keywords: Boron nitride nanocages, Hydrogen storage, Endohedral doping, Density functional theory.

\section{INTRODUCTION}

Utilization of huge amounts of fossil fuels as energy source creates a crucial danger to the environment. Therefore, scientists have been investigating safer alternatives for a long time. Hydrogen is one of the most important environment-friendly energy source (or energy carrier) since it is clean, sustainable, renewable and replaceable with fossil fuels ${ }^{1}$. Unfortunately, there are several technical and scientific difficulties concerning usage of hydrogen as a fuel ${ }^{2}$. The proper storage of hydrogen is the most critical problem waiting for a solution. In general, there are three possible ways for reversible hydrogen storage in high volumetric and gravimetric amounts e.g., (a) physical storage in high-pressure gas cylinders or in cryogenic tanks as liquid hydrogen (conventional methods), (b) chemical storage as metal and complex hydrides and (c) adsorption on some solid materials having high surface area, such as carbonaceous and non-carbonaceous nanosheets, nanotubes, nanoporeous adsorbents and zeolites (physisorption) $)^{3-6}$. In the beginning, carbon nanotubes (CNTs), which were discovered by Iijima in $1991^{7}$, had been considered very promising hydrogen storage materials due to initial experimental studies ${ }^{8-11}$. However, more recent studies ${ }^{12-14}$ indicated that the hydrogen uptake of these materials were much lower than the values measured in the previous studies and it is widely accepted that to be able to reach the DOE target of hydrogen storage capacity by usage of pure carbon based materials is practically impossible due to their weak interaction with hydrogen ${ }^{15}$. Therefore, the focus of hydrogen storage studies have diverted on boron nitride $(\mathrm{BN})$ nanocages ${ }^{16,17}$ and boron nitride nanotubes (BNNTs), discovered in $1995^{18}$, which have stronger interaction with hydrogen molecules compared to carbon nanotubes due to their polar B-N bonds. As expected, several experimental ${ }^{19,20}$ and theoretical studies showed that boron nitride nanotubes have better hydrogen storage capability than carbon nanotubes and they can store hydrogen up to $4.2 \mathrm{wt} \%$ at ambient conditions $(\sim 10 \mathrm{MPa})^{21}$. Sun et al..$^{22}$ computationally predicted that while $\mathrm{B}_{36} \mathrm{~N}_{36}$ nanocage structures can store up to 18 hydrogen molecules ( $4 \mathrm{wt} \%$ gravimetric density), 15 of the stored hydrogen escape from the cage according to molecular dynamics calculations performed at $300 \mathrm{~K}$, so they concluded that the $\mathrm{B}_{36} \mathrm{~N}_{36}$ cage may not be suitable as a practical hydrogen storage material at room temperature. In a recent article by $\mathrm{Li}$ et $a .^{23}$, it was reported that a microporous/ mesoporous boron nitride material called HBBN-1 can store hydrogen up to $5.6 \mathrm{wt} \%$ under somewhat moderate $3 \mathrm{MPa}$ pressure and more importantly it was shown that $84 \%$ of adsorbed hydrogen can be released when lowering the hydrogen partial pressure to nearly atmospheric conditions. Accordingly, boron nitride nano structures can be considered as possible candidates for hydrogen storage and they still worth to investigate.

The purpose of the present work is to computationally investigate stabilities of the complexes formed from the $\mathrm{B}_{12} \mathrm{~N}_{12}$, 
$\mathrm{B}_{24} \mathrm{~N}_{24}, \mathrm{~B}_{36} \mathrm{~N}_{36}, \mathrm{~B}_{48} \mathrm{~N}_{48}$ and $\mathrm{B}_{60} \mathrm{~N}_{60}$ nanocages endohedrally doped with hydrogen molecules by employing density functional theory methods. In fact, determination of maximum hydrogen storage capacity of these boron nitride nanocages is out of our scope in this study since filling a nanocage with large amount of hydrogen molecules will make the resultant complex rather unstable. Our main aim is to show that the nanocages under consideration form stable $\mathrm{nH}_{2} @ \mathrm{~B}_{\mathrm{m}} \mathrm{N}_{\mathrm{m}}$ complexes and their stability increases when more and more hydrogen molecules enter to the structure as endohedral cavity of nanocage increases. In other words, we intended to find a relation between size of nanocage and number of hydrogen molecules located inside nanocage forming the most stable complex. In addition, the performance of the $\omega \mathrm{B} 97 \mathrm{X}-\mathrm{D}$, PBE1PBE and B3LYP functionals for such weak-interaction systems are to be discussed.

\section{COMPUTATIONAL METHODOLOGY}

The $\mathrm{B}_{\mathrm{m}} \mathrm{N}_{\mathrm{m}}$ nanocages $(\mathrm{m}=12,24,36,48,60)$ were selected as the hosts where hydrogen molecules were endohedrally doped. All of these nanocages include only tetragonal and hexagonal connections in their geometries, except for $\mathrm{B}_{60} \mathrm{~N}_{60}$ nanocage that has only two octagonal connections in addition to other two types of connections. The $\mathrm{B}_{12} \mathrm{~N}_{12}, \mathrm{~B}_{36} \mathrm{~N}_{36}$ and $\mathrm{B}_{48} \mathrm{~N}_{48}$ nanocages are the lowest energy conformers while the $\mathrm{B}_{24} \mathrm{~N}_{24}$ nanocage lies $2.4 \mathrm{kcal} / \mathrm{mol}$ above the lowest energy conformer ${ }^{24}$. The most stable conformer for $\mathrm{B}_{24} \mathrm{~N}_{24}$ and $\mathrm{B}_{60} \mathrm{~N}_{60}$ were not chosen because they have octagonal and decagonal connections, respectively, making these nanocages relatively in appropriate for hydrogen storage purpose because of hydrogen escaping probability.

All $\mathrm{nH}_{2} @$ host complexes presented in this study include non-covalent interactions between hydrogen molecules and atoms of the nanocages ( $\mathrm{B}$ and $\mathrm{N}$ atoms). It has been shown that the $\omega \mathrm{B} 97 \mathrm{X}-\mathrm{D}$ functional ${ }^{25}$ gives reasonable accuracy for thermochemistry of the complexes including non-covalent interactions ${ }^{26}$. In a review article by Grimme ${ }^{27}$, the performance of $\omega$ B97X-D functional in calculation of non-covalent interactions was evaluated as "extraordinarily well". In order to check the validity of these assertion for our systems, the single point second order Møller-Plesset Perturbation theory (MP2) calculations were performed on the $\mathrm{B}_{24} \mathrm{~N}_{24}$ nanocage and the results confirmed the reliability of $\omega \mathrm{B} 97 \mathrm{X}-\mathrm{D}$ (Table-1). Thus, the $\omega \mathrm{B} 97 \mathrm{X}-\mathrm{D}$ functional was employed as the optimization method throughout the study together with 6-31G(d) basis set. All of the complexes, host and hydrogen molecules were initially optimized at $\omega$ B97X-D/6-31G(d) level. The electronic energies of all species were refined with single point $\omega \mathrm{B} 97 \mathrm{X}-$ $\mathrm{D} / 6-31+\mathrm{G}(\mathrm{d}, \mathrm{p})$ calculations at the optimized geometries.

It is well-known that the B3LYP functional is the widely accepted standard density functional theory method for a lot of systems including nano structured material and its efficiency in modeling exohedral and endohedral adsorption of several alkaline earth cations in $\mathrm{B}_{12} \mathrm{~N}_{12}$ nanocage has been demonstrated in a recent computational study ${ }^{28}$. In addition, DFT$\mathrm{PBE}_{\mathrm{PBE}}{ }^{29}$ has been considered a suitable calculation method for the systems having non-covalent interactions. In the present study, the performances of these two methods are aimed to compare with that of $\omega \mathrm{B} 97 \mathrm{X}-\mathrm{D}$. For that reason, additional single point energy calculations on the optimized geometries were also performed by using the B3LYP and PBE1PBE functionals employing 6-31+G(d,p) basis set.

To determine stability of the $\mathrm{nH}_{2} @$ host complexes, their formation energies (stabilization energies) were calculated from eqn. 1:

$$
\Delta \mathrm{E}=\left[\mathrm{E}_{\mathrm{nH}_{2} @ \text { host }}-\left(\mathrm{E}_{\text {host }}+\mathrm{nE}_{\mathrm{H}_{2}}\right)\right]
$$

where $\mathrm{E}_{\mathrm{n} \mathrm{H}_{2} @ \text { host }}, \mathrm{E}_{\text {host }}$ and are the electronic energies of the complex, host and hydrogen molecules, respectively. A negative value of formation energy $(\Delta \mathrm{E})$ indicates stability of complex since hydrogen molecules prefer being inside nanocage rather than being away from it. If there is an increase in the $\Delta \mathrm{E}$ value while hydrogen doping, this indicates stability loss of nanocage, but decrease in the $\Delta \mathrm{E}$ value shows that nanocage becomes more and more stable due to accepting hydrogen molecules.

All calculations were performed with Gaussian 09 computational chemistry suite ${ }^{30}$.

\section{RESULTS AND DISCUSSION}

The $\omega \mathrm{B} 97 \mathrm{X}-\mathrm{D} / 6-31 \mathrm{G}(\mathrm{d})$ level optimized geometries of the $\mathrm{B}_{12} \mathrm{~N}_{12}, \mathrm{~B}_{24} \mathrm{~N}_{24}, \mathrm{~B}_{36} \mathrm{~N}_{36}, \mathrm{~B}_{48} \mathrm{~N}_{48}$ and $\mathrm{B}_{60} \mathrm{~N}_{60}$ nanocages, the hosts for hydrogen molecules and the most stable $\mathrm{nH}_{2} @$ host complexes are depicted in Figs. 1 and 2, respectively. Moreover, the stability curves and the formation energies for $\mathrm{nH}_{2} @$ host complexes obtained from three different density functional theory functionals are also given in Fig. 3 and Table-1, respectively. Table-1 also includes stabilization energies per hydrogen molecule, $\Delta \mathrm{E} / \mathrm{nH}_{2}(\mathrm{kcal} / \mathrm{mol})$.

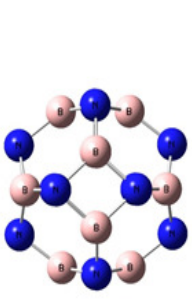

$\mathrm{B}_{12} \mathrm{~N}_{12}$

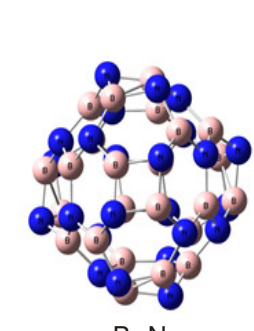

$\mathrm{B}_{24} \mathrm{~N}_{24}$

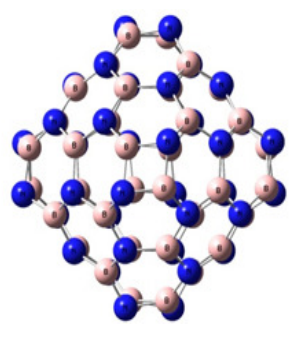

$\mathrm{B}_{36} \mathrm{~N}_{36}$

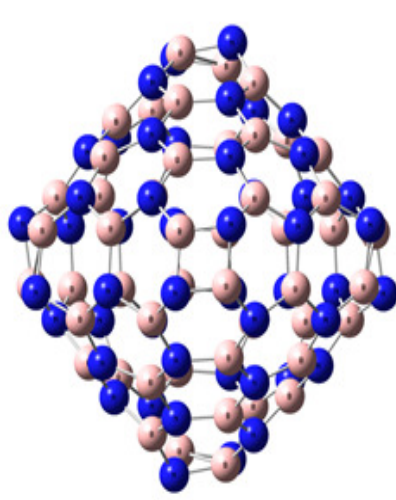

$\mathrm{B}_{48} \mathrm{~N}_{48}$

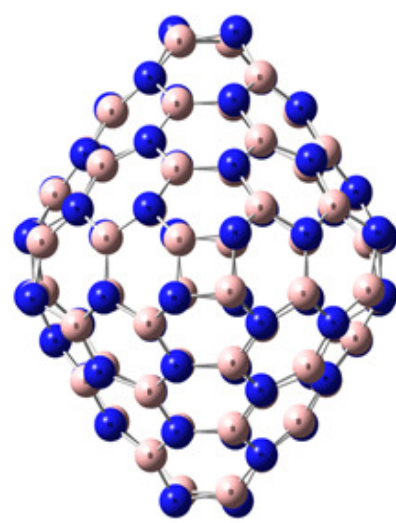

$\mathrm{B}_{60} \mathrm{~N}_{60}$
Fig. 1. Stable geometries of the host nanocages $\left(\mathrm{B}_{\mathrm{m}} \mathrm{N}_{\mathrm{m}}\right.$, where $\mathrm{m}=12,24$, $3648,60)$ optimized with the DFT- $\omega$ B97X-D method 


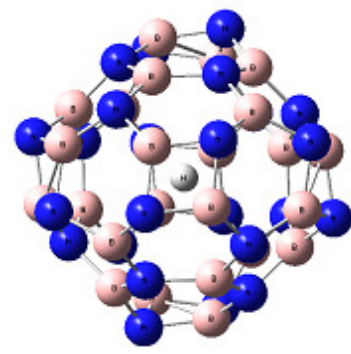

$\mathrm{H}_{2} @ \mathrm{~B}_{24} \mathrm{~N}_{24}$

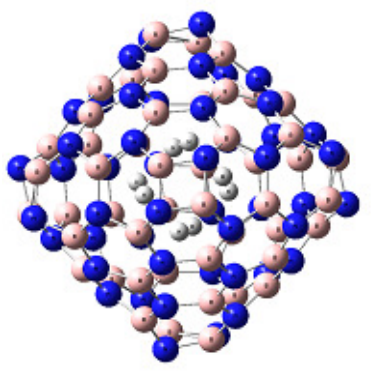

$4 \mathrm{H}_{2} @ \mathrm{~B}_{48} \mathrm{~N}_{48}$

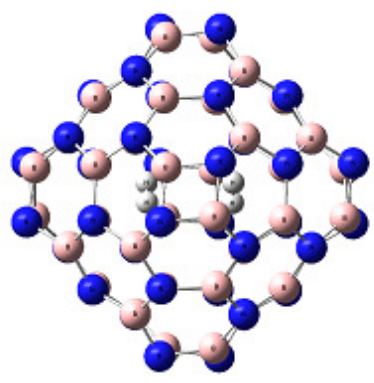

$2 \mathrm{H}_{2} @ \mathrm{~B}_{36} \mathrm{~N}_{36}$

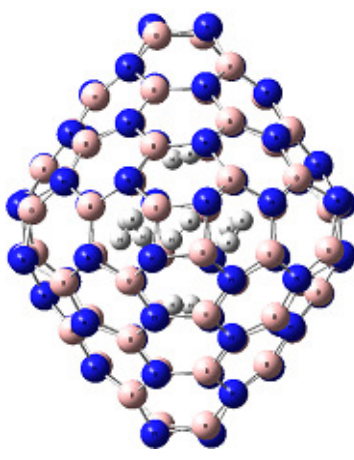

$7 \mathrm{H}_{2} @ \mathrm{~B}_{60} \mathrm{~N}_{60}$
Fig. 2. $\omega B 97 X-D$ optimized geometries of the most stable $\mathrm{nH}_{2} @$ host complexes

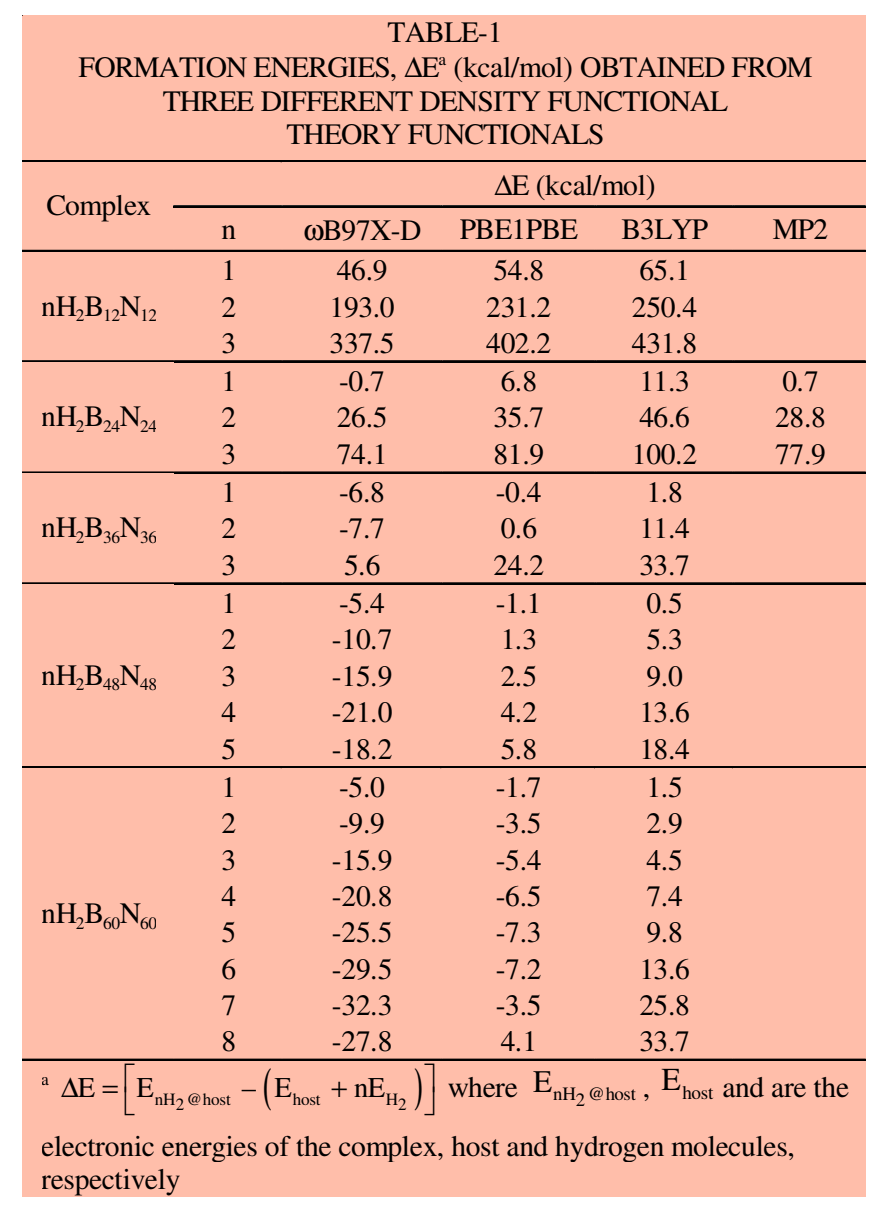

As mentioned in computational methodology part, the MP2/6-31+G(d,p) level single point energy calculations were performed on the $\mathrm{nH}_{2} @ \mathrm{~B}_{24} \mathrm{~N}_{24}$ complex geometries optimized at $\omega \mathrm{B} 97 \mathrm{X}-\mathrm{D} / 6-31 \mathrm{G}(\mathrm{d})$ level to check the reliability of the $\omega B 97 X-D$ method. Table-1 indicates that the stabilization energies of the $\mathrm{nH}_{2} @ \mathrm{~B}_{24} \mathrm{~N}_{24}$ complexes predicted by $\omega \mathrm{B} 97 \mathrm{X}$ $\mathrm{D}$ are rather close to the MP2 results while the PBE1PBE and B3LYP results are considerably away from them. These results as well as the previous studies ${ }^{26,27}$ are accepted as the indication of better performance of $\omega \mathrm{B} 97 \mathrm{X}-\mathrm{D}$ for non-covalent interaction cases. Therefore, the $\omega \mathrm{B} 97 \mathrm{X}-\mathrm{D}$ results were treated as the best results and the performances of B3LYP and PBE1PBE methods were evaluated accordingly.

We first discuss the stability of the complexes. It is seen from Fig. 3a, incorporation of even only one hydrogen molecule into the $\mathrm{B}_{12} \mathrm{~N}_{12}$ nanocage creates an unstable complex, as expected, because of being the smallest nano structure under study. Addition of the second and third hydrogen molecules inside this nanocage increases the hydrogen moleculenanocage atom repulsive interaction and destabilizes the complex much further. Each hydrogen molecule addition into $\mathrm{B}_{12} \mathrm{~N}_{12}$, creates rather huge destabilization, one can consider that the $\mathrm{B}_{12} \mathrm{~N}_{12}$ nanocage may not be suitable for endohedral hydrogen doping, at all. The $\mathrm{B}_{24} \mathrm{~N}_{24}$ nanocage has larger endohedral cavity than $\mathrm{B}_{12} \mathrm{~N}_{12}$, so it is possible to form stable hydrogen molecule containing complexes. Indeed, the results of $\omega \mathrm{B} 97 \mathrm{X}-\mathrm{D}$ indicate that the complex is slightly energetically favorable when it is accommodating one hydrogen molecule (Fig. 3b). Further hydrogen molecule additions destabilize the complexes but their instabilities are not as high as those encapsulated by $\mathrm{B}_{12} \mathrm{~N}_{12}$.

The $\mathrm{B}_{36} \mathrm{~N}_{36}$ complexes are energetically favorable up to third hydrogen molecule addition. One- and two-hydrogen molecule insertions create the stable complexes whereas the addition of one more hydrogen molecule destabilizes the complex (Fig. 3c). The stabilization energies of $\mathrm{H}_{2} @ \mathrm{~B}_{36} \mathrm{~N}_{36}$ and $2 \mathrm{H}_{2} @ \mathrm{~B}_{36} \mathrm{~N}_{36}$ are -6.8 and $-7.7 \mathrm{kcal} / \mathrm{mol}$, respectively. Sun et al. ${ }^{22}$ claimed that the stability of $\mathrm{H}_{2} @ \mathrm{~B}_{36} \mathrm{~N}_{36}$ and $2 \mathrm{H}_{2} @ \mathrm{~B}_{36} \mathrm{~N}_{36}$ complexes are 0.0 and $7.1 \mathrm{kcal} / \mathrm{mol}$, respectively, leading to destabilization of the complex upon second hydrogen doping. These results totally contradict with our $\omega$ B97X-D results while they are rather similar to the results of PBE1PBE. Recent computational studies $^{31,32}$ reveal that the PW91 functional, like PBE1PBE, is unable in the correct prediction of weak intermolecular interactions. Thus, the contradicting results of $\omega B 97 X-D$ and PW91 can be explained by lack of efficiency of PW91 in prediction of non-covalent interaction. Additionally, it is important to point out that $2 \mathrm{H}_{2} @ \mathrm{~B}_{36} \mathrm{~N}_{36}$ having lower energy than $\mathrm{H}_{2} @ \mathrm{~B}_{36} \mathrm{~N}_{36}$ implies the $\mathrm{H}_{2}-\mathrm{H}_{2}$ interaction being attractive and decrease overall potential energy of the system. However, addition of one more $\mathrm{H}_{2}$ to the $2 \mathrm{H}_{2} @ \mathrm{~B}_{36} \mathrm{~N}_{36}$ system that makes the $\mathrm{H}_{2}$ molecules closer to each other will increases the potential energy since the $\mathrm{H}_{2}-\mathrm{H}_{2}$ interaction becomes repulsive. Hence, the most stable complex for a specific nanocage will be the complex containing maximum number of hydrogen molecules where the $\mathrm{H}_{2}-\mathrm{H}_{2}$ interaction is still attractive.

The stability of the $\mathrm{nH}_{2} @ \mathrm{~B}_{48} \mathrm{~N}_{48}$ complexes increases until five hydrogen molecules doped inside the nanocage. The most stable $\mathrm{B}_{48} \mathrm{~N}_{48}$ complex is $4 \mathrm{H}_{2} @ \mathrm{~B}_{48} \mathrm{~N}_{48}$ whose stabilization energy is predicted as $21.0 \mathrm{kcal} / \mathrm{mol}$. Similarly, the $\mathrm{B}_{60} \mathrm{~N}_{60}$ nanocage that has the largest internal cavity among the studied 

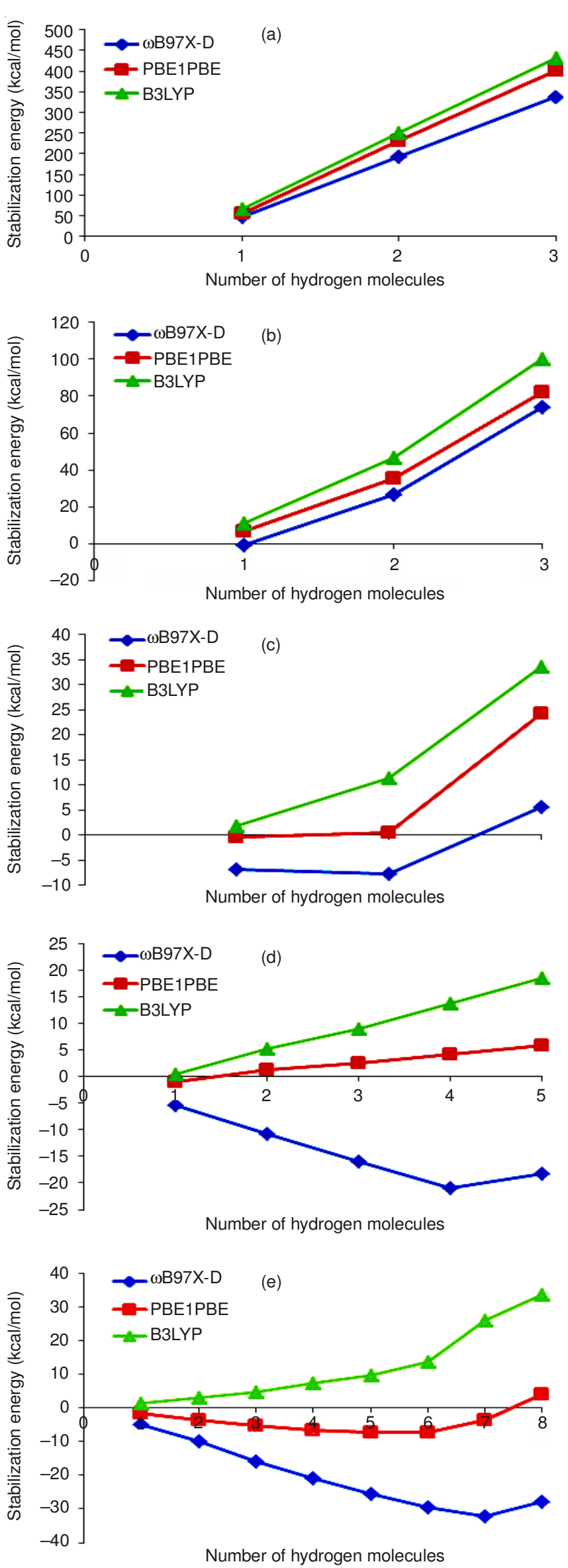

Fig. 3. Stability curves for $\mathrm{nH}_{2} @$ host complexes obtained from B3LYP, PBE1PBE and $\omega$ B97X-D functionals structures can accommodate seven hydrogen molecules and the resulting complex, $7 \mathrm{H}_{2} @ \mathrm{~B}_{60} \mathrm{~N}_{60}$, becomes the most stable one with stabilization energy of $-32.3 \mathrm{kcal} / \mathrm{mol}$. As a result, the $\omega B 97 X-D$ method predicted that the $\mathrm{H}_{2} @ \mathrm{~B}_{24} \mathrm{~N}_{24}$, $2 \mathrm{H}_{2} @ \mathrm{~B}_{36} \mathrm{~N}_{36}, 4 \mathrm{H}_{2} @ \mathrm{~B}_{48} \mathrm{~N}_{48}$ and $7 \mathrm{H}_{2} @ \mathrm{~B}_{60} \mathrm{~N}_{60}$ complexes are the most stable hydrogen-boron nitride complexes. According to these estimations, we built up a relation between nanocage size and the number of hydrogen molecules doped inside the most stable complex of each nanocage, shown in Fig. 4. The best equation that fits the data was also determined as:

$$
\mathrm{n}=0.0025 \mathrm{~m}^{2}-0.0369 \mathrm{~m}+0.2
$$

where $\mathrm{n}$ is the number of hydrogen molecules in the most stable complex of each nanocage and $\mathrm{m}$ is the number of (boron nitride) unit in the nanocage. Eqn. 2 implies that more stable $\mathrm{nH}_{2} @ \mathrm{~B}_{\mathrm{m}} \mathrm{N}_{\mathrm{m}}$ complexes will form as the size of nanocage increases due to growth in internal cavity which can accommodate hydrogen molecules.

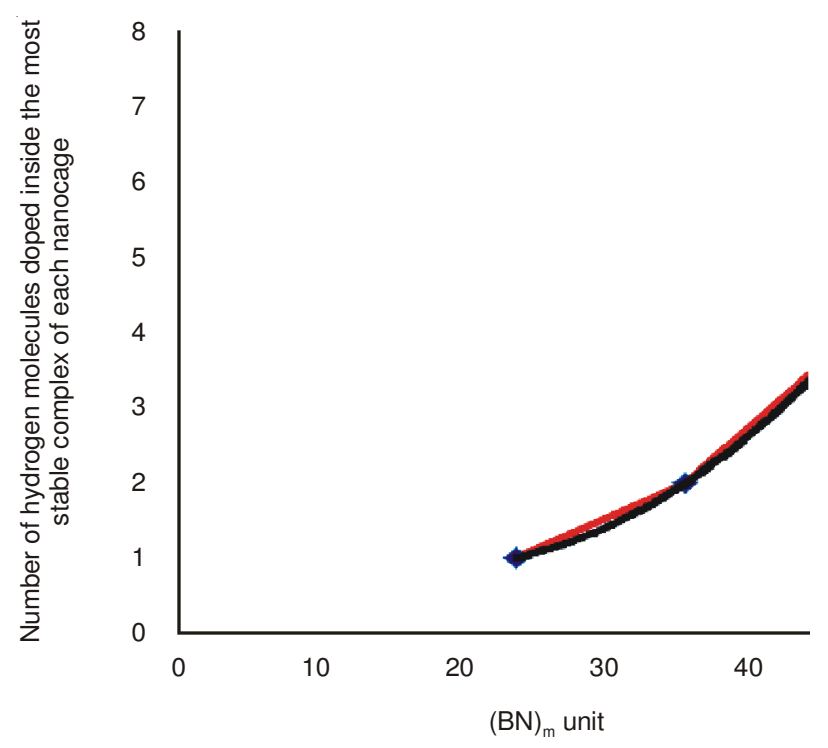

Fig. 4. Relation between nanocage size and the number of hydrogen molecules doped inside the most stable complex of each nanocage obtained from the DFT- $\omega$ B97X-D results

Fig. 3 clearly shows that the $\omega$ B97X-D functional gives the lowest stabilization energy curves compared to B3LYP and PBE1PBE for all the host molecules. The B3LYP hybrid functional erroneously predicts that none of the boron nitride nanocage studies here can form a stable $\mathrm{nH}_{2} @ \mathrm{~B}_{\mathrm{m}} \mathrm{N}_{\mathrm{m}}$ complex, even the largest nanocage, $\mathrm{B}_{60} \mathrm{~N}_{60}$. Actually, this is an expected result since B3LYP does not include non-covalent interactions at all. Hence, this density functional theory functional seems to be an inappropriate one for especially endohedral hydrogen doping systems where non-covalent interactions are extremely important. Furthermore, the PBE1PBE functional predicted that (i) any number of hydrogen molecules will not fit in $\mathrm{B}_{12} \mathrm{~N}_{12}$ and $\mathrm{B}_{24} \mathrm{~N}_{24}$ resulting stable complexes, (ii) like $\mathrm{B}_{36} \mathrm{~N}_{36}$, the $\mathrm{B}_{48} \mathrm{~N}_{48}$ nanocage can enclose only single hydrogen molecule (iii) the most stable complex that can be constituted by $\mathrm{B}_{60} \mathrm{~N}_{60}$ is $4 \mathrm{H}_{2} @ \mathrm{~B}_{60} \mathrm{~N}_{60}$. These results indicate that the overall performance of PBE1PBE is better than B3LYP, but worse than $\omega \mathrm{B} 97 \mathrm{X}-\mathrm{D}$ for the endohedral hydrogen doped boron nitride nanocage systems. 


\section{Conclusion}

In this study, we have investigated stabilities of the $\mathrm{nH}_{2} @ \mathrm{~B}_{\mathrm{m}} \mathrm{N}_{\mathrm{m}}$ complexes $(\mathrm{m}=12,24,36,48,60)$ by employing several density functional theory methods. Our main purpose was to determine the most stable $\mathrm{nH}_{2} @ \mathrm{~B}_{\mathrm{m}} \mathrm{N}_{\mathrm{m}}$ complexes for each nanocage structure and to find out number of hydrogen molecules doped inside the most stable complex of each nanocage being how dependent to size of nanocage. In addition, we aimed to determine what density functional theory functional being the most appropriate for the $\mathrm{nH}_{2} @ \mathrm{~B}_{\mathrm{m}} \mathrm{N}_{\mathrm{m}}$ systems involving non-covalent interactions. Our findings can be summarized as follows:

(a) There is no stable complex for the smallest nanocage, $\mathrm{B}_{12} \mathrm{~N}_{12} .1,2,4$ and 7 hydrogen molecules can endohedrally be doped in the $\mathrm{B}_{24} \mathrm{~N}_{24}, \mathrm{~B}_{36} \mathrm{~N}_{36}, \mathrm{~B}_{48} \mathrm{~N}_{48}$ and $\mathrm{B}_{60} \mathrm{~N}_{60}$ nanocages, respectively, by making the resultant complexes energetically the most favorable for the corresponding nanocage.

(b) The variation of number of hydrogen molecules doped inside the most stable complex of each nanocage with nanocage size obeys the quadratic equation given as eqn. 2 .

(c) The $\omega \mathrm{B} 97 \mathrm{X}-\mathrm{D}$ functional has the best performance among the employed B3LYP, PBE1PBE and $\omega$ B97X-D methods in accurate modeling of the systems involving $\mathrm{H}_{2}$ doping in boron nitride nanocages. PBE1PBE most probably overestimates repulsion of hydrogen molecules doped in nanocages. B3LYP is inappropriate for calculations of these systems since it produced rather poor results.

In conclusion, we can safely say that boron nitride nano materials still maintain their positions among of the most important hydrogen storage materials.

\section{ACKNOWLEDGEMENTS}

This study is supported Scientific Research Projects of Ege University through the project no 09/FEN/046. The numerical calculations reported in this paper were partially performed at TUBITAK ULAKBIM, High Performance and Grid Computing Center (TRUBA resources).

\section{REFERENCES}

1. http://www.eere.energy.gov/topics/hydrogen_fuel_cells.html.

2. D.A.J. Rand and R.M. Dell, Hydrogen Energy, Challenges and Prospects (RSC Energy Series), Royal Society of Chemistry; Cambridge, UK, Chap. 5, p. 146 (2008).

3. L. Schlapbach and A. Zuttel, Nature, 414, 353 (2001).

4. A. Zuttel, A. Remhof, A. Borgschulte and O. Friedrichs, Phil. Trans. R. Soc. A., 368, 3329 (2010).

5. J. Zheng, X. Liu, P. Xu, P. Liu, Y. Zhao and J. Yang, Int. J. Hydrogen Energy., 37, 1048 (2012).
6. A. Züttel, Mater. Today, 6, 24 (2003).

7. S. Iijima, Nature, 354, 56 (1991)

8. A.C. Dillon, K.M. Jones, T.A. Bekkedahl, C.H. Kiang, D.S. Bethune and M.J. Heben, Nature, 386, 377 (1997).

9. C. Liu, Y.Y. Fan, M. Liu, H.T. Cong, H.M. Cheng and M.S. Dresselhaus, Science, 286, 1127 (1999).

10. Y. Ye, C.C. Ahn, C. Witham, B. Fultz, J. Liu, A.G. Rinzler, D. Colbert, K.A. Smith and R.E. Smalley, Appl. Phys. Lett., 74, 2307 (1999).

11. P. Chen, X. Wu, J. Lin and K. Tan, Science, 285, 91 (1999).

12. R.T. Yang, Carbon, 38, 623 (2000).

13. H. Kajiura, S. Tsutsui, K. Kadono, M. Kakuta, M. Ata and Y. Murakami, Appl. Phys. Lett., 82, 1105 (2003).

14. M. Ritschel, M. Uhlemann, O. Gutfleisch, A. Leonhardt, A. Graff, Ch. Täschner and J. Fink, Appl. Phys. Lett., 80, 2985 (2002).

15. G.E. Froudakis, Mater. Today, 14, 324 (2011).

16. T. Oku, A. Nishiwaki and I. Narita, Sci. Technol. Adv. Mater., 5, 635 (2004).

17. T. Oku, I. Narita and A. Nishiwaki, Mater. Manuf. Process., 19, 1215 (2004).

18. N.G. Chopra, R.J. Luyken, K. Cherrey, V.H. Crespi, M.L. Cohen, S.G. Louie, and A. Zettl, Science, 269, 966 (1995).

19. P. Wang, S. Orimo, T. Matsushima, H. Fujii and G. Majer, Appl. Phys. Lett., 80, 318 (2002).

20. R. Ma, Y. Bando, H. Zhu, T. Sato, C. Xu and D. Wu, J. Am. Chem. Soc., 124, 7672 (2002)

21. C. Tang, Y. Bando, X. Ding, S. Qi and D. Golberg, J. Am. Chem. Soc., 124, 14550 (2002).

22. Q. Sun, Q. Wang and P. Jena, Nano Lett., 5, 1273 (2005).

23. J. Li, J. Lin, X. Xu, X. Zhang, Y. Xue, J. Mi, Z. Mo, Y. Fan, L. Hu, X. Yang, J. Zhang, F. Meng, S. Yuan and C. Tang, Nanotechnology, 24, 155603 (2013).

24. H.-S. Wu, X.-Y. Cui, X.-F. Qin, D.L. Strout and H. Jiao, J. Mol. Model., 12, 537 (2006).

25. J.-D. Chai and M. Head-Gordon, J. Chem. Phys., 128, 084106 (2008).

26. J.-D. Chai and M. Head-Gordon, Phys. Chem. Chem. Phys., 10, 6615 (2008).

27. S. Grimme, WIREs Comput. Mol. Sci., 1, 211 (2011).

28. J. Beheshtian, M.B. Tabar, Z. Bagheri and A.A. Peyghan, J. Mol. Model., 19, 1445 (2013).

29. C. Adamo and V. Barone, J. Chem. Phys., 110, 6158 (1999).

30. M.J. Frisch, G.W. Trucks, H.B. Schlegel, G.E. Scuseria, M. A. Robb, J.R. Cheeseman, G. Scalmani, V. Barone, B. Mennucci, G.A. Petersson, H. Nakatsuji, M. Caricato, X. Li, H.P. Hratchian, A.F. Izmaylov, J. Bloino, G. Zheng, J.L. Sonnenberg, M. Hada, M. Ehara, K. Toyota, R. Fukuda, J. Hasegawa, M. Ishida, T. Nakajima, Y. Honda, O. Kitao, H. Nakai, T. Vreven, Jr., J.A. Montgomery, J.E. Peralta, F. Ogliaro, M. Bearpark, J.J. Heyd, E. Brothers, K.N. Kudin, V.N. Staroverov, R. Kobayashi, J. Normand, K. Raghavachari, A. Rendell, J.C. Burant, S.S. Iyengar, J. Tomasi, M. Cossi, N. Rega, J.M. Millam, M. Klene, J.E. Knox, J.B. Cross, V. Bakken, C. Adamo, J. Jaramillo, R. Gomperts, R.E. Stratmann, O. Yazyev, A.J. Austin, R. Cammi, C. Pomelli, J.W. Ochterski, R.L. Martin, K. Morokuma, V.G. Zakrzewski, G.A. Voth, P. Salvador, J.J. Dannenberg, S. Dapprich, A.D. Daniels, Ö. Farkas, J.B. Foresman, J.V. Ortiz, J. Cioslowski, and D.J. Fox, Gaussian 09, Revision A.1, Gaussian, Inc., Wallingford CT (2009).

31. Y. Liu, Y. Zhao, F. Li and Z. Chen, J. Comput. Chem., 34, 121 (2013).

32. E.R. Johnson and G.A. Dilabio, Chem. Phys. Lett., 419, 333 (2006). 